\title{
LA EPISTEME ZAPATISTA \\ Otra forma de ver el mundo y hacer política*
}

\section{Victoria Inés Darling}

(D) https://orcid.org/0000-0001-5678-5175

(1) Universidade Federal da Integraçăo Latino-Americana (UNILA), Foz do Iguaçu - PR, Brasil. E-mail: victoria.darling@unila.edu.br

DOI: $10.1590 / 3510408 / 2020$

Desde 1994 y de manera intermitente, los zapatistas de Chiapas sorprenden a la sociedad civil nacional e internacional con comunicados, análisis de coyuntura, anuncios de encuentros, festivales, denuncias del estado de situación de los militares que cercan los municipios, así como con noticias relativas a cambios en su modo de organización política. De este modo, han creado una suerte de diálogo que, aún

\footnotetext{
* Este artículo es resultado del trabajo de investigación realizado en la estancia postdoctoral en la Facultad de Ciencias Sociales de la Universidad de Buenos Aires. Felizmente, conté para su realización con apoyo de una beca posdoctoral de CONICET. Agradezco sinceramente la orientación del Prof. Hernán Ouviña así como los comentarios y cuestionamientos de los y las compañeras del Seminario Obligatorio del Posdoctorado, coordinado por la estimadísima Prof. Leonor Arfuch.
}

Artigo recebido em: 28/01/2019

Aprovado em: 24/11/2019 dando cuenta de tácticas para lidiar con los medios de comunicación dominantes, a través de medios alternativos, los mantiene en comunicación con simpatizantes, adherentes a la Sexta Declaración de la Selva Lacandona y seguidores de la causa autonómica.

Lo cierto es que en el derrotero de sus formas de organización, como resultado del proceso de acumulación política, los zapatistas lograron crear un modo de hacer política que va a destiempo de la institucionalidad política mexicana. No sólo proclamaron una revolución en 1994, en pleno apogeo neoliberal de la región, sino que realizaron en la práctica un proyecto de autonomía del Estado a través de formas organizativas diferentes a las tradicionalmente construidas por la democracia representativa - partidos políticos, sindicatos o asociaciones. En 2018, sin más, presentaron una precandidatura independiente a la Presidencia de la República, indígena y mujer, vocera del Congreso Nacional Indígena. 
Esta excepcionalidad política que va a destiempo de la institucionalidad estatal, se cristaliza en la creación de espacios de socialización propios. La conformación de espacios comunitarios para discutir asuntos colectivos, la definición de sus siete principios (servir y no servirse; representar y no suplantar; construir y no destruir; obedecer y no mandar; proponer y no imponer; convencer y no vencer; y, bajar y no subir), la organización para la deliberación en Juntas de Buen Gobierno, así como la creación de comisiones asignadas a tareas específicas, tienen un origen común: la resistencia al orden coactivo y coercitivo del Estado colaboró en el proceso de creación de estructuras de gobierno autónomo con características propias de una forma de realizar "lo político" de manera original. Habría en estos procesos elementos de una otredad respecto de las relaciones sociales hegemónicas, elementos políticos y metapolíticos. De alguna manera, esta otredad se manifiesta en el modo de ver y entender las dinámicas colectivas, los vínculos humanos, los valores, el poder y la Naturaleza.

Partimos del entendimiento de lo político como momento de subversión de lo instituido, como surgimiento de un antagonismo que expresa el carácter contingente y no acabado del orden social. En términos de Laclau (2010) se trata de una experiencia ubicua -que está presente en todas partes y al mismo tiempo-, en que se constituye un sujeto político que asume la forma de exterior constitutivo, o sea, un elemento que no puede ser aceptado o incorporado al orden hegemónico. Como diferencia que representa una negatividad inherente a un exterior constitutivo, articula detrás de sí otras diferencias que podrían ser explicadas a través de cadenas de equivalencias. De aquí la multiplicidad de sentidos y conceptos propios hilvanados por los zapatistas.

Para Laclau, el antagonismo surge cuando se enfrentan dos sistemas que no comparten ningún lenguaje o discurso, aunque sí se disputan algo en común. Es la negación de un orden y el señalamiento del límite de dicho orden.

Límite que pone en crisis la identidad, es una experiencia de fracaso no con un más allá, sino al interior de lo social como algo que lo subvierte, que destruye su aspiración a constituir una presencia plena o realidad objetiva (Ghilini, 2015, p. 141)

Desde este punto de vista, a partir de su aparición pública, el movimiento zapatista como sujeto colectivo de cambio, expandió las vías de discusión y prácticas de lo político permitiendo una aprehensión diferente del camino revolucionario, y con esto, ampliando y diversificando sus posibilidades de realización.

En este marco, abrimos el interrogante sobre las raíces y condicionantes de este antagonismo. ¿Qué aspectos provenientes de los pueblos indígenas que confluyen en el Ejército Zapatista de Liberación Nacional (EZLN) colaboraron en crear la excepcionalidad de lo político zapatista que tanto cautiva a nacionales y extranjeros? ¿Qué saberes y tradiciones, elementos de diferentes formas de ver el mundo, alimentan la singularidad política de los y las zapatistas? Siguiendo estas interrogaciones, proponemos hilvanar elementos antropológicos, místicos, de orden comunitario, que se condensan en la forma política zapatista. Entendemos que estas ideas y prácticas forman parte de la autonomía y constituyen una episteme propia. La episteme zapatista es la síntesis, una trama de saberes y elementos culturales diversos, preexistentes a la conformación del movimiento, que a partir de su articulación cristalizó formas políticas singulares ${ }^{1}$.

Una idea hipotética que se encuentra en la superficie de lo expuesto sostiene que los zapatistas constituyen una amalgama original formada por diferentes pueblos preexistentes a la Conquista, como choles, tzeltales, tzotziles y tojolabales, que encontraron cohesión en el proceso de agrupamiento de la entonces guerrilla zapatista de inicios de los años ochenta en Chiapas, siguiendo el derrotero de un ciclo más largo de luchas que tuvo a la finca -o hacienda- como eje articulador de la dominación. Con el paso del tiempo, estos pueblos indígenas habrían confluido construyendo una subjetividad colectiva -compuesta por elementos culturales propios-, signada por el antagonismo con el Estado al gestar una forma distintiva de construir lo político.

El objetivo de las siguientes páginas es identificar algunos de esos elementos, saberes específicos y legados que los pueblos que confluyen en el EZLN realizan, conformando una cultura política diferenciada de 
la nacional-estatal hegemónica. Se trata de pensar la diferencia que se genera por el propio proceso colonial-modernizador que produce unos espacios de fronteras, unas exterioridades, unos conocimientos subalternizados (no completamente definidos) (Escobar, 2011, p. 2). Allí es posible si no encontrar al menos profundizar en las preguntas sobre la posibilidad de alcanzar un proyecto de descolonización a nivel epistemológico.

Recuperamos en esta línea datos obtenidos en el trabajo de campo realizado en México, así como de una recuperación de textos provenientes de la historiografía de Chiapas, en particular del investigador belga Jan de Vos (1980), del ensayista chiapaneco Jesús Morales Bermúdez (1983) y del filósofo, teólogo y lingüista alemán Karl Heinz Herman -o simplemente- Carlos Lenkersdorf (1996; 2008). La investigación se enmarca en la diversidad de estudios que apuntalan la existencia de epistemologías latinoamericanas con características propias, diferentes de la tradicional europeo-occidental, siguiendo las críticas y contribuciones de la red de intelectuales del Grupo Colonialidad/Modernidad que fundaron los estudios decoloniales ${ }^{2}$. Este abordaje entiende que la colonialidad es la cara oculta de la modernidad en tanto proyecto histórico, patrón de poder y de saber. En este marco, los criterios epistémicos de producción de conocimiento se encuadran en una visión eurocentrada que cińe la interpretación de la realidad social reproduciendo contenidos, temas, problemas y prejuicios. (Lander, 2000; Dussel, 2000; Castro Gomez y Grosfoguel, 2007; Walsh, 2000; Mignolo, 2010).

\section{La finca: orden y disciplinamiento}

La población indígena y campesina de Chiapas vivió bajo el sistema centrado en la finca o hacienda por más de cien años. Las ciudades de la región, sus mercados e instituciones administrativas, se constituyeron como extensión de dicha organización de la producción, del trabajo y del poder. No es posible entender una forma de organización y articulación social chiapaneca sin comprender a fondo "la finca" en tanto categoría política que designa una forma de ejercicio de la dominación caracterizada por la concentración de poder bajo el dominio de patrones religiosos, políticos y privados.
La finca, en términos de articulación económico-política en una unidad de producción, recurrió para la explotación a mano de obra semi-esclava, en su mayoría de indígenas. Además, se sirvió de las estructuras del Estado para la instalación de un orden opresivo, de prácticas que comprendían francos abusos de poder. La hacienda surgió a principios del siglo XVII, en algunos casos se extendió al siglo XVIII, y en zonas específicas como el sur de México, se expandió aceleradamente durante el siglo XIX. Bajo esta forma de ejercicio de la dominación, la religión jugó un rol legitimador del orden, reproduciendo y promoviendo la jerarquía social del patronazgo.

La hacienda era una unidad autónoma, una verdadera microsociedad que contenía todos los elementos económicos, políticos, militares e ideológicos para su reproducción (...) los hacendados eran los dueños de la tierra y los "indios" devinieron (un tipo particular de) campesinos (Ansaldi y Giordano, 2012, p. 115).

Se trataba de superficies en que se plantaba extensivamente y cuya función era consolidar su autosuficiencia. Las políticas que acompañaron la consolidación de las relaciones sociales de la finca produjeron en México la eliminación de las formas comunales de uso y propiedad de la tierra, ya que su subsistencia resultaba inútil a los fines del incipiente modelo primario exportador. En esa línea,

(...) se afirmó un ordenamiento jurídico basado en la noción de derechos individuales básicos y derechos de propiedad. El nuevo marco jurídico sirvió de andamiaje legal para el proceso de modernización (Ansaldi y Giordano, 2012, p. 119).

El proceso de consolidación de las relaciones de producción capitalistas y el modo de vida conocido como liberal tuvo una dimensión colonial de conquista. Como afirma Edgardo Lander (2000), además de la expulsión de los campesinos y los siervos de la tierra, la economía requería de una transformación total de los individuos, los cuerpos y las formas sociales. 
La aparición de un sistema de haciendas, esto es, un mecanismo de interrelación conflictiva entre la hacienda del terrateniente y las unidades de producción de los campesinos e indígenas que tenían relación de renta o producción a cambio de un salario, se dio tardíamente en la región, en el siglo XIX. Los conflictos generados al interior del sistema se daban entre el terrateniente y los campesinos y entre las unidades económicas de los campesinos dentro de la finca y las de afuera. Los recursos en disputa eran generalmente recursos naturales necesarios para la producción, como agua y bosques, y fuerza de trabajo.

La finca como modo de organización social y político en Chiapas comenzó su decadencia en concomitancia con la formación del campesinado, en los años 70 del siglo XX, al calor de la organización colectiva y el trabajo de reorganización social posterior a la reforma agraria. Aún cuando existen posturas que sostienen que las relaciones sociales basadas en la finca aún persisten como rastros de un pasado que permanece vigente, existe un consenso establecido en torno a su proceso de declive en los 70 y su efectiva finalización en enero de 1994.

En las fincas hay cárceles, en las cárceles hay cepos. En los cepos hay encarcelados que no están encauzados. Los indios no entienden el lenguaje del fiscal, ni el juez entiende el de los encarcelados (...) $\mathrm{Al}$ desapoyo se añade la ignorancia y a la ignorancia el terror interiorizado. Un indio que reclama sus derechos es un terrorista. Provoca irritación y da miedo, afirmaba Pablo González Casanova en el discernimiento de las causas del levantamiento indígena zapatista.

El modelo de ocupación del territorio, la posesión autónoma de la tierra y la organización política rebelde gestaron un nuevo orden en el que las comunidades indígenas asumieron un rol protagónico logrando el respeto y reconocimiento de sus formas organizativas. Lo cierto es que el desplazamiento del orden patronal, definitivamente obedeció a las acciones de los zapatistas, quienes, además de tomar las cabeceras municipales en 1994, ocuparon renombradas haciendas. En la zona tojolabal de los alrededores de Comitán por ejemplo, las tomas se incrementaron luego del levantamiento. Las famosas fincas de San Mateo y El Retiro fueron objeto de ocupación. El ex gobernador Absalón Castellanos (1980-1986), reconocido finquero de la zona, infelizmente recordado por su rol opresor a líderes campesinos, fue secuestrado por los zapatistas con posterioridad a la toma de la cabecera de Las Margaritas. Impulsados por estas acciones, otros grupos campesinos se sumaron a la ocupación y a la disputa por la obtención de una parcela de tierra.

(...) un grupos de campesinos del ejido Saltillo invadió las tierras y la casa que quedaban de esa finca y el rancho vecino llamado San José (...) En el caso de San Joaquin, el dueño permitió a algunos campesinos tomar parte de las tierras a cambio de que dejaran la casa intacta, como permanece hasta hoy. Para el periodo posterior al levantamiento de 1994, la gran mayoría de pequeñas fincas fueron eliminadas (Escalona, 2009, p. 61).

Previo a la visibilización pública de las acciones del EZLN, la Central Independiente de Obreros Agrícolas y Campesinos (CIOAC) en los años ochenta, ya había realizado un trabajo de politización y organización. En la zona tojolabal, la CIOAC junto con grupos de catequistas habían impulsado actividades de educación, formación política y movilización (Escalona, 2009). No obstante, es a partir de la aparición del EZLN que los campesinos se dividieron en grupos que apoyaban y se identificaban con la causa zapatista sumándose a las acciones políticas de reorganización comunitaria.

La lucha por la tierra es $y$ ha sido una causa fundante de la movilización de los y las campesinas de Chiapas para su organización y participación política. Los ejidos, las organizaciones de ejidos y las autoridades que de esta organización comunitaria se derivan, como los comisarios ejidales y asambleas ejidatarias constituyen actores centrales para entender las relaciones sociales y políticas que se fraguan en las comunidades. Asimismo, las organizaciones de ejidos se convirtieron en canales de comunicación entre regiones rurales distantes que atraviesan situaciones de precariedad. Su agrupamiento, conocimiento mutuo y activación colaboró con el fin del régimen de la finca 
como forma de organización conservadora y excluyente, propia de una dinámica colonial de apropiación del territorio, y a su vez, con el aprendizaje de formas nuevas de politización largamente anheladas.

\section{Hombres y mujeres de la tierra del maíz}

"La tierra brota del ombligo de Chiujtiat, (...) en la tierra nos renovamos como las flores, como cada nuevo ciclo agrí́cola; tierra es nuestra piel, el olor de nuestras mujeres, su flujo menstrual también es del color de la tierra $y$, finalmente, de la tierra brota y crece el maíz" Oración chol

Los indígenas choles, o winik habitan la zona de Tabasco, Guatemala y el norte de Chiapas, en particular la región de Sabanilla, Tumbalá, Salto del agua, Tila, Palenque y Ocosingo, colindando con la selva Lacandona. Los cronistas espańoles los denominaron choles malinterpretando el vocablo ch'ol tan que hacía referencia a quien hablaba su lengua, sin embargo son conocidos de este modo hasta el día de hoy. Entre ellos se denominan winiky entre ellas xixik, término con el que también llaman a otros indígenas. Ellos y ellas explican su existencia y trayectoria a partir del maíz, alimento sagrado, origen y fuente de vida.

Los choles mantienen relación de larga data con el pueblo tzeltal de Los Altos de Chiapas, y con los tzotziles, con quienes tienen modos de trabajo y producción similares. Los tzeltales se caracterizan por modos de vida y socialización restringida, son 'más herméticos' en sus formas de vinculación y en menor medida aceptan relaciones interculturales. Los tzotziles, en cambio, por su llegada más reciente a la zona del norte del estado, a causa de las disputas religiosas de San Juan Chamula -que culminaron con la expulsión de un importante número de jóvenes debido a causas religiosas ${ }^{3}$-, son más proclives a organizarse por fuera de las comunidades. Debido a los problemas derivados de la ocupación de tierras que encontraron al instalarse, rompieron con las estructuras sociales de su pueblo vinculándose con otras comunidades en búsqueda de caminos políticos propios.

La relación fundamental con la tierra es condición de existencia para los mayas, pueblo originario, cultura madre de los choles, tzotziles, tzeltales y tojolabales. La agricultura es, asimismo, base de su concepción del mundo. Se trata de una relación con la tierra que excede su producción para el sustento, la obtención de recursos y la comercialización, y comprende la existencia, su sentido y temporalidad.

En las tierras que se asientan, los choles plantan maíz, frijol y café. También cuidan animales que sirven de alimento y carga. Como sus condiciones de vida son precarias, en algunos momentos del año muchos de ellos deben migrar al estado de Tabasco o a la capital del estado de Chiapas, Tuxtla Gutiérrez, para ser empleados temporalmente. De hecho, los finqueros del café, para los tiempos de cosecha aún hoy

prefieren contratar a los tzeltales de Huixtán y de Oxchuk, ya que por su miseria acentuada, el desconocimiento de la lengua de los patrones y hasta por la eventualidad del trabajo que van a realizar, se vuelven más sumisos y aceptan cualquier exceso en su explotación (Morales, 1999, p. 27).

No obstante estas condiciones, los choles tienen una rica tradición de resistencia y organización. En 1976, y luego en 1978 y 1994, realizaron invasiones colectivas de tierra, así como marchas pacíficas y no tan pacíficas a Simojovel, Tuxtla y al Distrito Federal (Morales, 1999) encontrando en la lucha intercomunitaria razones y demandas que condujeron a una profundización de sus vínculos. Aún cuando la desposesión de tierra fue la razón principal de estrechamiento de relaciones entre los pueblos choles, tzeltales y tzotziles, el grado de marginación y las condiciones de vida precarias subsecuentes aunaron sus lazos (De Vos, 1994).

Existen razones de peso para esta resistencia, muchos de estos grupos en su confrontación con los finqueros de la zona debieron emigrar. El recuerdo de las matanzas de Naquem (Huitiupam) en 1976, en el Xoc (Sabanilla) en 1977 y en Woloncham (Sitalá) 
en 1979 alimenta una extendida memoria larga de masacres, represiones y asedio que en gran medida abonó en el estrechamiento de lazos políticos y sociales.

Hacia 1960 y 1970 los tzeltales y tzotziles se vieron forzados a migrar a la Selva Lacandona debiendo aprender a vincularse y colonizar un territorio hasta entonces poco conocido en términos de recursos y medios para la vida. Siguiendo sus pasos, fueron comerciantes y vendedores ambulantes que llevaban mercancías elementales de provisión en mulas como machetes, sal, azúcar y petróleo (De Vos, 1988). Ellos son quienes en su proceso de circulación y asentamiento fueron poblando en conjunto con los indígenas la zona sur del estado.

Las ciudades del centro de Chiapas también guardan herencias del paso de los choles y tzeltales, quienes, despojados de tierra, ofrecieron su fuerza de trabajo a los finqueros en tiempos coloniales. El suceso histórico que signó su devenir es antiguo y tiene origen en las leyes de Reforma de los años 1855 y 1863 que, en tiempos de Benito Juárez, condujo al poblamiento del estado por parte de latifundistas. Llegaron compañías extranjeras, inglesas y alemanas, que talaron bosques y despoblaron territorios enteros. Estaban interesados en la producción maderera, no obstante, debido a los costos de extracción, hacia 1874 se enfocaron al cultivo del café. Los choles se vieron despojados de sus tierras y comunidades de pertenencia debiendo encasillarse en fincas para sobrevivir (Basauri, 1931).

Las huellas de las antiguas fincas aún perduran, así como las imponentes maquinarias de café provenientes del extranjero, cargadas entonces en hombros por los indígenas. Muchos murieron en el camino, de este modo se estructuró una industria cafetalera que, impulsada por enormes fincas de apellidos foráneos, tuvo como pilar fundamental el trabajo de choles y tojolabales ${ }^{4}$.

El fin de las grandes fincas habría tenido un impulso inicial con la política de reforma agraria del General Lázaro Cárdenas, quien, en 1933, habiendo recorrido la zona a lomo de mula, mandó a concretar la política de redistribución transformando enormes fincas en reducidos terrenos de un máximo de 200 hectáreas. El resto, sería transformado en ejidos y repartido en comunidades. Desde entonces los pueblos indígenas reificaron sus organizaciones comunitarias.

Los procesos sociohistóricos conjuntos entre choles, tzeltales y tzotziles llevaron a prácticas comunitarias entrelazadas de confrontación con los finqueros y las instituciones que legitiman su poder. La cohesión $\mathrm{y}$ articulación intercomunitaria fue crucial para encontrarse hermanados en los tiempos iniciales de conformación del EZLN. La memoria larga de matanzas y resistencias, las luchas por la ocupación de tierras y las migraciones forzadas, constituyen elementos comunes que, ensamblados, construyeron una visión crítica sobre su propia realidad.

\section{Familia y religiosidad}

Cada comunidad chol, tzotzil, tzeltal y tojolabal tiene festividades propias dedicadas a la devoción de santos católicos, legado de la época colonial. Se trata de un sincretismo de creencias mayas y cristianas del que se deriva la mayordomía. En cada fecha conmemorativa, para celebrar al santo patrono, es elegido un mayordomo que consiste en el título honorífico que designa a quien creará las condiciones sociales y materiales para llevar adelante la celebración. Con el tiempo, quien mayor cantidad de mayordomías haya realizado, tendrá mayor reconocimiento social. Asimismo, principal es aquel que ha desarrollado algún cargo en la comunidad.

Las mayordomías, con alférez y capitanes, varían de pueblo en pueblo, alcanzando grados diversos que, mixturadas con el linaje, configuran estructuras de enorme complejidad ${ }^{5}$. Algunas tienen peso a la hora de la elección de representantes a cargos municipales, incluso. Actualmente, el mayordomo es elegido según las fiestas y por su propia voluntad, en tanto que, anteriormente el mayordomo era nombrado con base en la riqueza de que fuera poseedor y según la acrecentara para asi mantener una regulación de bienestar comunitario (Morales, 1999: 40). Sus funciones son materiales y simbólicas, de prestigio y reconocimiento, así como de responsabilidad de mantener limpia la ermita en que el ícono del santo se encuentra durante el año, y también debe reunir el dinero para sufragar los costos de la celebración. 
Existe un intenso debate antropológico en relación al sistema de cargos y sus funciones en las comunidades de la zona central de Chiapas (Paniagua, 2008). Lo cierto es que es posible considerar la estructura de las mayordomías como un efectivo reducto cultural de los indígenas frente a la vida al exterior de las comunidades (Fravre, 1973) y como un mecanismo de permanencia en la indianidad, en tanto forma de resistencia a la discriminación que la sociedad ladina ejerce.

El complejo sistema de cargos que juega un papel tan importante en la cultura indígena, no existe entre los ladinos. Bajo el disfraz de los santos católicos, la concepción de la divinidad es marcadamente politeísta mientras que el catolicismo de los ladinos es más monoteísta (...) el culto del tipo revivalista de los "santos parlantes" es casi exclusivamente una actividad indígena (Vogt, 1992, p. 35).

La estructura de las mayordomías tiene elementos que nutren los principios guiando las formas las formas organizativas del EZLN, en particular, en la importancia simbólica de la asunción de cargos y en la enorme responsabilidad con que son asumidas las tareas. No sólo importa ser voluntariamente responsable y trabajar sin pago a cambio, sino también, saber obedecer a una comunidad que manda y de la que se obtendrá un reconocimiento social, no material.

La autoridad es ejercida mediante la persuasión y la influencia más que a través de ordenamientos. La posesión de un cargo (función religiosa) en los grupos indígenas es una fuerza niveladora algo más que un simple factor de la jerarquía, ya que, aunque un cargo confiere prestigio a quien lo tiene, impone también el gasto de grandes sumas de dinero, de manera que desalienta la concentración de la riqueza (Vogt, 1992, p. 33-34).

En un contexto de construcción de autoridad, representación religiosa y legitimidad social, la familia, por su parte, cobra especial relevancia. En la organización del EZLN, en la distribución de cargos y responsabilidades colectivas, en la conformación de comisiones y Juntas de Buen Gobierno, la unidad familiar de hecho, apoya y da sustento. La asunción de responsabilidades no descansa en la esfera de la acción individual, por el contrario, las mujeres que trabajan en la casa, o bien los varones, los nińos, los y las ancianas, al calor de prácticas de reciprocidad y acompańamiento, ejercen también el cargo asumido. Se trata de tareas colectivas, comunitarias y familiares, solidarias y desinteresadas. En ese sentido, fundan una cultura política comunitaria. Lo familiar tiende a la estructuración comunitaria alimentando el lazo de pertenencia y cohesionando la institución creada.

\section{El Otro tiempo}

En las Juntas de Buen Gobierno zapatistas, participan de manera rotativa aquellos y aquellas delegadas que la propia comunidad de los municipios autónomos eligen. Se trata de un mandato más complejo que el de mera representación: es un cargo de responsabilidad al que debe responderse con capacidad de mediar y liderar procesos y conflictos sociales.

Todas las decisiones colectivas tienden a orbitar alrededor de la institución de la asamblea, desde la elaboración de propuestas para el plantío en áreas colectivas, la deliberación sobre sugerencias y consultas de los municipios o Juntas de Buen Gobierno, la colonización de tierras por nuevos individuos, la alternancia de franjas de tierra para descanso o la relocalización de familias, el uso de bosques y recursos naturales, las propuestas de trabajo con la sociedad civil, el conflicto entre cónyugues, las disputas personales, la organización de fiestas y actividades religiosas, etc. (Brancaleone, 2015, p. 304. Traducción propia)

Son designados para esos roles hombres y mujeres de cada comunidad, aunque muchas bases de apoyo femeninas aún tienen dificultades para aceptar la asunción de cargos debido su postergación histórica y la falta de dominio del español de Castilla.

La toma de decisiones en las Juntas de Buen Gobierno asume un proceso de ida y vuelta en cada 
Caracol o región autónoma. Muchas veces se realiza una consulta desde la comunidad que discute la Junta y luego, se regresa la cuestión problemática a la comunidad para repensar el modo de resolver el tema. En otras oportunidades, la discusión horizontal demora más de lo esperado ya que el debate busca alcanzar consenso entre todos los miembros de la Comisión especial de tratamiento del tema, o Junta. Se trata de procesos decisorios con temporalidad propia, que siguen los tiempos de maduración de las propias comunidades. En ningún caso se designa una instancia administrativa-burocrática, sino que la decisión es de ellos y ellas, y para ellos y ellas. La tradición indica que los ancianos son los primeros que deben ser escuchados. Aunque muchas veces sus relatos no mantengan la secuencia lógica que los jóvenes esperan, la temporalidad que reivindican jerarquiza la toma de conciencia sobre la decisión a tomar. Las narrativas tradicionales asumen aquí una importante tarea.

Esta concepción del tiempo, ajena a la prisa de la política occidental, antítesis de la política estatal, tiene raíces profundas de respeto a los procesos propios de cada comunidad y de armonía con los ciclos de la naturaleza. Los pueblos mayas desarrollaron su cultura en relación con el maíz. Así como las relaciones sociales tienen base y explicación en el desarrollo de las fuerzas productivas, el maíz y su proceso de producción da sentido a las formas de vida y relación social. No es de extrañar que los juegos, deportes, actividades de formación y la salud, tengan al maíz como elemento simbólico presente, inserto en cualquiera de sus formas.

Los choles, así como los mayas, los tzotziles y los tzeltales, desarrollaron el "humanismo del maíz". En las comunidades autónomas zapatistas, desde antes del amanecer, las mujeres trituran los granos remojados durante la noche para fundirlos con cal y harina, y amasar las tortillas. Luego, se les da forma manualmente, se cuecen, se aguarda el punto justo de cocción, se apartan, se secan, se guardan y se separa el maíz para el pozol, bollito de harina gruesa disuelto en agua que será el alimento enviado a la milpa donde los hombres, en su mayoría, trabajan la tierra para la siembra y cosecha del frijol.
El maíz es cosechado en tiempo preciso y en su abundancia, almacenado para cuando la tierra no pueda dar lo necesario. El maíz se almacena en un espacio seco, se resguarda, se utiliza para alimentar los animales de cuidado, y se comparte en las fiestas. La temporalidad es propia, ajena a la del trabajo asalariado. Se trata de un ciclo continuo, que respeta la naturaleza y va al compás de su derrotero: tiempo de roza, de arduo trabajo para arar la tierra, cortar malezas y preparar la siembra. Tiempo de limpia, de cuidado y espera. Tiempo de cosecha, de planificación, de organización colectiva para el transporte y preparación del lugar de almacenamiento. Fiesta del maíz nuevo, de cosecha y abundancia.

No hay espacio social comunitario que no esté rodeado de milpas, el maíz es constitutivo y constituyente de un orden junto al monte, el agua, la nube, el animal, la tierra, el viento, los cuales tienen funciones específicas, con tiempos propios y en armonía. En varios comunicados zapatistas (EZLN, 2014) se menciona una temporalidad que va a contracorriente y a destiempo de la nacional-estatal, de calendarios y geografías occidentales, predominantemente urbanas.

El EZLN no sólo recupera las tradiciones indígenas de un tiempo que sigue los tiempos de la naturaleza, de ida y vuelta en la toma de decisiones y respeto al silencio (EZLN, 2012), sino también un tiempo en el que es posible encontrarse con la Naturaleza, y en ella, con el otro.

\section{La escucha como acto político}

Los indígenas tojolabales habitan la zona central de Chiapas. Tojolabal deriva del nombre de su lengua: tojol $a b^{\prime}$ al, que significa idioma verdadero. Provienen también de la gran familia de los pueblos mayas. Tojol remite a lo genuino que incluso remite a un tiempo indeterminado, recto, correcto (una tortilla tojol es una tortilla que está en su punto justo).

La lengua explica una parte importante de la visión de mundo tojolabal, y a través de ella puede inferirse un modo político de comprender y actuar en sociedad. En las lenguas indoeuropeas, la discursividad, el habla, tiene carácter unidireccional. Se habla -a otra persona-, se escucha -el mensaje-, 
luego, se responde. Quien escucha, tiene la libertad de recibir aquello que se le dice. De esa manera no sólo nos comunicamos, sino que recibimos y transmitimos entre tantos mensajes, los contenidos que consideramos importantes para el proceso de educación. Los sujetos-maestros-educadores dicen su palabra para que los alumnos-objetos-educandos la repitan.

Por informativa que sea, la forma que asumimos en el habla española no es comunicativa, no es intersubjetiva. Para los tojolabales, en cambio, las frases son bidireccionales ${ }^{7}$. El ejemplo más claro sería: "Lo dije, ustedes escucharon" (Lenkersdorf, 2012). Se trata de una comunicación intersubjetiva. Los tojolabales no pueden percibir la comunicación ni hablar de ella a no ser que sea dialógica, requiriendo que sujetos se interrelacionen con sujetos y exigiendo complementariedad entre iguales.

Una frase indígena en contexto de no entendimiento de un joven enfermo, sería/fue la siguiente: "mixkab 'tik ja skúmal la loktor jumasá já yuj mi xyab' kujtik... mini jas wa xnaátik". En español: "Nosotros los tojolabales no entendemos el idioma de los médicos que a su vez tampoco nos entienden". La capacidad de escuchar implica el entendimiento, no la emisión de ruidos. Y, al mismo tiempo, el entendimiento significa respeto. Las fases de comunicación intersubjetiva son: decir, escuchar, entender, respetar (Lenkersdorf, 2012, p. 34). El diálogo es expresado por una estructura intersubjetiva, se realiza entre iguales y sólo el entendimiento expresa el respeto entre ambos. El respeto, el diálogo, abarca múltiples espacios de la vida indígena, las conversaciones diarias, los cuentos, los anuncios públicos.

Karl Lenkersdorf, gran hombre y conocedor de los pueblos tojolabales, con quienes compartió vida $\mathrm{y}$ años de trabajo cristalizados en ricas contribuciones académicas, sostuvo que la cosmovisión maya tojolabal, con su estructura lingüística, cuestiona los fundamentos de nuestra cultura.

Nuestro modo de ver el mundo no es nada universal sino provinciano y limitado. Por consiguiente, las estructuras de nuestra lengua tampoco son universales, sino limitadas y obedecen a la manera en que percibimos el mundo (Lenkersdorf, 2012, p. 48).

La realidad intersubjetiva de los tojolabales tiene múltiples expresiones además de las discursivas. Como dato figurativo, cabe aquí un paréntesis: para los tojalabales, el caminar es una suerte de arte. No se camina "así nomás". Existe una técnica para hacerlo con gracia y elegancia, si se quiere. Se trata de una técnica que no se enseña pero que se aprende. Mover adecuadamente las extremidades, balancear el cuerpo, tener un determinado ritmo en los pasos dados, lograr alcanzar un compás, un movimiento armónico, estético. De manera semejante parece operar la realidad, se acompańa una caminata de la que no se habla pero enseña, y, con las mayores dificultades debido a un punto de partida que surge de lo desconocido, se aprende.

Parte de la intersubjetividad del mundo tojolabal es también la realidad cósmica indivisible. No se admite la dualidad sagrado/profano. Vivimos en una realidad cósmica, sagrada de la cual somos corresponsables. Lugares sagrados como cuevas, ermitas, recursos para disfrutar y no vender, son sagrados.

Ahora bien, es en las asambleas en que se toman las decisiones donde la intersubjetividad se expresa con metodología peculiar. Particularmente, en las zonas tojolabales, la autoridad comunitaria zapatista anuncia el motivo de la reunión y la pauta a resolver, y al mismo tiempo expresa que al enunciarla, la comunidad responde. Se trata de una asamblea de escuchadores (Lenkersdorf, 2008). La comunidad responde a las razones expuestas en la asamblea tomando la palabra. Cada uno propone lo que piensa sobre el tema presentado. Uno a la vez. Todos y todas. Cambian sus lugares para hablar y se escucha, y luego, se regresa al diálogo grupal.

Poco a poco, menos y menos personas hablan y escuchan. Finalmente se produce un gran silencio. Todos se callan. Ya no hay aportaciones que hacer. Después de un tiempo de silencio, uno de los asambleístas levanta la voz y afirma en tojolabal: "Nosotros pensamos, nosotros decidimos y nosotros vamos a hacer (Lenkersdorf, 2008, p. 76). 
Así, las decisiones son intersubjetivas y no se detiene la deliberación sino hasta lograr el consenso de todos y todas las participantes. De hecho, la forma de tomar decisiones se condice con la percepción comunitaria de la autoridad. El poder de gobernar no se entrega a las autoridades, sino que se mantiene horizontalmente entre los asambleístas que "se reparten el poder" y representan a la autoridad máxima, que es, claro, la asamblea. El poder es nosótrico, la autoridad es ejercida a partir de y en consenso asambleario. La función de la autoridad es, entonces, la de escuchar detenidamente cada aspecto de la deliberación, de modo de recordar con posterioridad, los consensos alcanzados y así poder cumplir con su tarea.

La escucha se realiza en etapas que cristalizan una democracia asamblearia, participativa y directa. Así como en las comunidades tojolabales, la asamblea es distintiva de la toma de decisiones y puesta al día de una importante cantidad de pueblos originarios de América Latina. No obstante, si los asambleístas no saben escuchar, la asamblea deja de tener sentido, no sirve a los fines de la política, se descompone la comunidad y por lo tanto, su poder. Como intentamos evidenciar, el acto de escuchar es una muestra de respeto en el marco de un diálogo entre dos personas. El acto de gobernar es el ejercicio de dicho respeto a nivel comunitario.

El poder nosótrico, a su vez, alcanza otras formas de expresión como el ejercicio de la justicia de manera comunitaria. La forma de administrar justicia entre los tojolabales se contrapone al concepto de justicia castigadora, punitiva y vengativa, heredada desde los primeros años del periodo colonial, y cuya mejor representación es la cárcel como castigo principal y generalizado (Fernández Christlieb, 2012, p. 43). La justicia restitutiva procura abrir a los delincuentes modos de reintegrarse al nosotros comunitario.

La participación de las mujeres zapatistas en las dinámicas de decisión política del movimiento, a su vez, tiene notas distintivas. Si bien con anterioridad al levantamiento zapatista ellas habian transitado por procesos que las formaron como sujetos mujeres (...) podemos notar que la adhesión al movimiento permite la modificación radical de sus formas de estar (Padierna Jiménez, 2013, p. 2). A su vez, el proceso de fortalecimiento de sus propias demandas y la cristalización de posturas diferenciadas en tanto mujeres, fue realizándose en la imbricación de las zapatistas con las demandas históricas del movimiento feminista en México.

Con ello podemos considerar que el discurso feminista es una fuente de interpelación para las zapatistas que se juega al lado de otros referentes (como el del propio EZLN), pero que mantiene rasgos que nos permiten argumentar una especificidad propia (Padierna Jiménez, 2013, p. 4).

Lo cierto es que algunas mujeres bases de apoyo, confiesan en pasajes de los relatos de la experiencia llamada La escuelita zapatista de 2014, que hasta hace poco tiempo las mujeres no participaban de las asambleas, y que cuando lo hacían, temían hablar en público. Desde hace aproximadamente veinte ańos las mujeres comenzaron a participar activamente de las reuniones, se trata de un proceso de afianzamiento y conquista de espacios que lentamente van logrando.

Para finalizar, cabe aclarar que en la deliberación no hay un tiempo definido, sino todo el que sea necesario. Se trata de un aprendizaje y escucha permanente.

El escuchar comunitario o colectivo funciona, porque existe el nosotros que forma comunidad. Funciona el escuchar porque a quienes se escucha son hermanos y hermanas que pertenecen al nosotros. Por eso, se les tiene confianza, se les escucha porque los respetan. Todos son nosótricos. Pero exactamente por esa razón, los opositores que suelen ser el grupo de los que dominan o los pudientes, se esfuerzan para que los escuchadores que suelen ser los de abajo no tengan la oportunidad de ser escuchados y de realizar proyectos fuera de los intereses de los de arriba (Lenkersdorf, 2008, p. 97).

Probablemente esta nota peculiar de los tojolabales signe el caminar preguntando de los zapatistas. 
La asamblea como espacio de autoridad y la escucha como medio, sin duda atraviesan el proceso expandiendo el horizonte democrático de quienes se sienten parte de sus demandas.

\section{Mitos que explican, justifican y orientan}

Los hombres indígenas no pueden vivir humanamente mientras exista un águila que los devore (...) y seres malignos que los engañen para matarlos y comer sus cuerpos. El propósito que guía las acciones de los protagonistas (de los mitos) es invertir dicha situación, es vencer al enemigo para restablecer así el orden de su mundo. (Alejos García, 1999)

Los mitos y las leyendas son discursos que contienen mensajes simbólicos que dan sentido a la vida en sociedad. Muchas veces, funcionan como modelos ideales de acción social, ejemplificando la conducta a los miembros de la comunidad a la que pertenecen. En Chiapas, la mayoría de las narrativas míticas no tienen un origen ni una temporalidad definida, aunque algunas de ellas se encuentran en la constelación de simbologías mayas y significados otorgados en el Popol Vuh, escritura del siglo XVI considerada sagrada por los quichés de Guatemala. Los relatos del Popol Vuh enfatizan los valores de la verdad y la no traición, la lucha y la muerte del enemigo.

La dimensión simbólica de la vida humana puede ser verbalizada en el discurso, cristalizada en un mito, en un rito, en un dogma, o incorporada a los objetos, a los gestos, a la postura corporal, y está siempre presente en cualquier práctica social (Durham, 1984, p. 72. Traducción propia)

El pensamiento mítico está constituido por una realidad simbólica y en su reproducción, se convierte en un modelo ejemplarizante de la pluralidad de acciones encaminadas a la búsqueda de trascendencia. De hecho, el pensamiento mítico es considerado la primera forma del pensamiento, (...) que da sentido al mundo desde el momento de nacer; es la primera forma de racionalidad que permite la inserción del ser humano en una familia y una comunidad particular; es la forma de pensamiento a partir de la cual, sólo con y a través de la mediación del lenguaje, posteriormente, puede llegarse a otras formas de pensamiento (Páez Martínez, 2011, p. 2).

De transmisión oral, los mitos recuerdan sucesos históricos destacando los valores heroicos de cada pueblo. El reparto de tierras en tiempos de Cárdenas es, por ejemplo, un tema frecuente en la discursividad chol, también el fin de las grandes fincas cafetaleras alemanas y norteamericanas que hasta los años 30 del siglo XX dominaron el norte del estado.

Las narrativas orales relatan que en aquella época los campesinos eran esclavos de los finqueros, sufrían castigos y realizaban reiterados intentos de fuga que culminaban muchas veces en azotes públicos, reprimendas o fosas con hormigas. El legado de estas narrativas indican que los relatos orales han sido portadores de mensajes liberadores, muchas veces utilizados como motivación para no dejarse vencer por la adversidad. La lucha contra las injusticias forma parte del alma de estos relatos que se actualizan reproduciéndose en la voz de quienes los relatan, otorgándole valor propio a la palabra. De la dimensión simbólica cobran realidad y se constituyen en guía y referencia de buena conducta.

El EZLN ha recuperado el valor de la palabra inmersa en mitos y narrativas tradicionales. La miríada de cuentos y fábulas, relatos de ancianos como el Viejo Antonio, primero, y de Durito después, no son más que el aggiornamento de una tradición indígena presente en la vida cotidiana y la socialización de las comunidades. La fuente de conocimiento de los mitos no sólo colabora en otorgar sentido, coherencia y justificación a sus acciones, sino que también les permite ingresar a los miembros de la comunidad en un campo simbólico propio, a veces cargado de humor, sarcasmo e ironía en el que el relato invita a sentirse parte.

Durito de la Lacandona y el viejo Antonio son personajes que guían a sus comunidades con la 
sabiduría de la tradición. A través de mitos sobre el origen del mundo, de las cosas y de los colores, interpretan las acciones y logran una explicación sobre el momento histórico que se vive. Se trata de la revalorización de la tradición oral, de la historia y con ella, de la necesidad de actualizar la memoria.

Un apartado propio debería tener el silencio en el discurso zapatista. En oposición a la cultura occidental que otorga una sobreestimada cantidad de significados a las palabras, los indígenas de Chiapas encuentran en el silencio múltiples sentidos.

En la tradición cultural maya, el silencio se concibe como matriz de lo que está por venir, antecede a la historia de los dioses. Si bíblicamente la palabra es fundadora, en esta tradición lo es el silencio (Rajchenberg y Héau-Lambert, 2004, p. 52)

La ausencia de palabras es diametralmente opuesta a decir nada, pues la palabra no es el único medio para decir, expresar o reclamar. Durante largos períodos de tiempo, a lo largo de su trayectoria, desde 1983, el movimiento zapatista se expresó a través del silencio. Fueron periodos extensos, de ausencia de manifestaciones públicas, de no participación en instancias políticas regionales ni internacionales. En cada uno de estos momentos, como en el tercer cuatrimestre de 2012, por ejemplo, la prensa argumentó una multitud de razones, hipótesis y versiones falsas. El fin del movimiento, la crisis de la Comandancia, la débil salud de Marcos, entre otras, fueron sólo algunas de las razones señaladas.

La ausencia en el espacio público de la voz zapatista fue, vez a vez, rellenada con discursos variopintos, razones imaginarias e hipótesis -las más de las vecesfallidas, por voceros de medios de comunicación, del gobierno e incluso, por investigadores de la academia.

En un mundo lleno de palabras, el silencio parece ser la nada: cuando la palabra se ausenta deja de haber significación, no se está diciendo nada (...) hay muchos códigos: un gesto, un andar, un baile y el mismo silencio son "lenguajes" y son, por consiguiente, formas de expresión de sentido. Cuando la voz calla, se está diciendo sin hablar (Rajchenberg y Héau-Lambert, 2004, p. 52).
Lo cierto es que, en tiempos de silencio, el zapatismo se ha organizado, recreado y repensado. Sin caer en la pretensión de otorgarle un sentido unívoco, el silencio en el marco de sus narrativas y discursividad, ha adquirido significados propios para su conformación interna, procesos de acumulación política y afianzamiento colectivo.

No es menos cierto que los zapatistas a través del silencio también enseñan. En numerosas instancias prácticas de la Escuelita Zapatista de 2014, así como en la marcha del 12 de diciembre de 2012 sobre San Cristóbal de las Casas, entre otras cuatro ciudades chiapanecas, la prescindencia de palabra, expuso un "silencio a voces".

...sin disparar ni un sólo tiro, sin armas, con nuestro sólo silencio, postramos de nuevo la soberbia de las ciudades cuna y nido del racismo y el desprecio. Si el primero de enero de 1994 miles de hombres $\mathrm{y}$ mujeres sin rostro atacaron $\mathrm{y}$ rindieron las guarniciones que protegían las ciudades, el 21 de diciembre del 2012 fueron decenas de miles que tomaron sin palabras los edificios desde donde se celebraba nuestra desaparición. El sólo hecho inapelable de que el EZLN no sólo no se había debilitado, mucho menos desaparecido, sino que había crecido cuantitativa y cualitativamente, hubiera bastado para que cualquier mente medianamente inteligente se diera cuenta de que, en esos 20 años, algo había cambiado al interior del EZLN y de las comunidades (EZLN, 2014, p. 3).

En la marcha, bajo una copiosa lluvia, $40 \mathrm{mil}$ zapatistas desfilaron con números en la frente dando cuenta de su magnitud y vigencia. Anunciaron "el derrumbe de su mundo y el resurgimiento del nuestro" maya zapatista. La fecha obedecía al 13 Baktún del antiguo calendario maya que auguraba el fin de un ciclo.

\section{La autonomía como construcción permanente}

Las comunidades zapatistas se encuentran organizadas en cinco Caracoles que cuentan con Juntas de Buen Gobierno, dispersas en el estado de Chiapas. Los Caracoles recibieron el nombre de Madre de los 
caracoles del mar de nuestros sueños, Resistencia hacia el nuevo amanecer, Torbellino de nuestras palabras, Caracol que habla para todos, y Resistencia y rebeldía para la Humanidad. ${ }^{8}$ Estos Caracoles nuclean a Municipios Autónomos Revolucionarios que cuentan con autoridades locales escogidas en y por las comunidades. Quienes participan de la vida comunitaria, sustento del movimiento, son considerados bases de apoyo, personas y familias identificadas con el zapatismo.

Los Municipios Autónomos constituyen una pieza aparentemente sincrética entre un municipio, tal y como se conoce en la dinámica estatal, y uno autónomo. De alguna manera, son el legado de los Acuerdos de San Andrés firmados en 1996, que no lograron cristalizarse por omisión sino traición del gobierno mexicano.

(...) lo que les dio visibilidad y presencia pública en 1998 fue la traición del gobierno a la palabra empeñada y la intensificación de la guerra: la masacre de Acteal y su secuela de millares de refugiados en el municipio de Chenalhó; el estrechamiento del cerco y las incursiones militares contra las comunidades; el despliegue y multiplicación de los grupos paramilitares y la ofensiva del gobierno estatal y federal contra los municipios rebeldes (Burguete Cal y Mayor, 2002, p. 122).

Lo cierto es que los Municipios Autónomos son gobernados por Consejos Autónomos que organizan a nivel zonal la salud, educación y producción material de las comunidades zapatistas. Las autoridades en los Consejos se vuelven responsables de los asuntos comunes, son resultado de asambleas a las que responden. Los cargos son rotativos, y no hay mayor reconocimiento que el respeto, pues no hay retribución por el trabajo de gobierno. A través de Comisionados, se imparte la justicia comunitaria, se resuelven conflictos diversos como disputas familiares, agrarias, robos de ganado o asuntos de la comunidad, relativos o no a la forma de ejercicio de la autonomía.

El otorgamiento de nombres propios a los espacios sociales que los zapatistas fundan, es un tema fundamental. James Scott, en su obra Los dominados y el arte de la resistencia (2000) desafía la idea de hegemonía gramsciana entendida como consenso tácito o consenso ideológico, afirmando que los dominados saben cómo y por quiénes son violentados en el ejercicio de la dominación, y debido a ello, como forma de resistencia, desarrollan formas sociales sutiles, muchas veces invisibles, de confrontar esa dominación. El chiste, la burla, el secreto a voces son formas de resistencia cotidianas, en este sentido. Ahora bien, William Roseberry recupera este cuestionamiento a la idea de hegemonía y señala con mayor precisión que el uso que Gramsci realiza del concepto de hegemonía es menos simbólico y más "material y político". Para Roseberry, en su lectura crítica de Gramsci, la hegemonía no sería una formación ideológica acabada y monolítica, sino un proceso político de dominación problemático, de lucha.

En esta acepción es que es posible comprender la sucesión de bautismos y búsquedas refundacionales a través de nombres y frases otorgados en las comunidades zapatistas, antes del Estado Nación mexicano.

Lo que la hegemonía construye no es, una ideología compartida, sino un marco común material y significativo para vivir a través de los órdenes sociales caracterizados por la dominación, hablar de ellos y actuar sobre ellos (Roseberry, 2002, p. 220).

De ese marco común forma parte el discurso, el lenguaje. O sea, la manera de hablar de las relaciones sociales establece los términos dentro de los cuales se pueden establecer las controversias y disputas.

"Madre de los caracoles del mar de nuestros sueńos", "Resistencia hacia el nuevo amanecer", "Torbellino de nuestras palabras", "Caracol que habla para todos" y, "Resistencia y rebeldía para la Humanidad", expresan diferentes miradas sobre la comunidad, sobre el Estado y la conformación de la nación. El estado se arroga el poder de dar nombre, de crear e imprimir mapas con marbetes sancionados por el Estado (Roseberry, 2002, p. 223). Los zapatistas e indígenas pueden reconocer ese derecho de nombrar, y a su vez, rechazar los nombres que el Estado les da. Así, los zapatistas con sus bautismos y propuestas refundacionales resisten ante palabras; y las palabras 
señalan y expresan relaciones y poderes materiales sociales, económicos y políticos de mayor envergadura.

Dispersos, en territorios distantes, los zapatistas cuentan también con un sistema de salud auto organizado, con promotores y promotoras que se capacitan y forman a su vez a compañeros y compañeras. Con un hospital de alta complejidad y clínicas que atienden a bases de apoyo y campesinos de la zona, se despliega una red de atención que disputa con el Estado territorios y adherentes. Existe una Coordinación de Salud a nivel municipal y representantes comunitarios en Comités de Salud locales, integrados por trabajadores de la salud, vacunadores, hueseras, y promotoras de salud reproductiva. Existen 25 Clínicas Regionales Autónomas, 200 Casas de Salud comunitarias y una clínica central. Se trata de una estructura que se construye desde abajo, construida por las propias comunidades y atendidas por personal de las mismas localidades.

Las unidades médicas de referencia, definidas como Clínicas Regionales Autónomas (...), en algunos casos son apoyados por médicos de Universidades o bien contratados, y su función es resolver lo posible o bien derivar a un segundo nivel, que de momento no existe en el SSAZ (Sistema de Salud Autónomo Zapatista), de tal forma que se recurre al del Sistema Nacional de Salud (Cuevas, 2007, p. 9).

Las comunidades cuentan también con un sistema escolar zapatista, con contenidos y pedagogías definidos por las comunidades, brindando educación definida acorde a sus necesidades, en su propia lengua. Hay escuelas de enseñanza fundamental $\mathrm{y}$ jardines de infantes. Las estructuras de justicia, salud, educación, así como las de organización de la producción y Juntas de gobierno, son autónomas esto quiere decir que se mantienen al margen del Estado y niegan cualquier posible injerencia de los gobiernos, municipal, estatal o federal. No reciben subsidios, tampoco políticas sociales ni ayudas en especias. Por otra parte, a lo largo de las últimas décadas, los zapatistas, resolvieron de manera airosa el desafío que impuso el relevo generacional de sus mandos y comandantes. Y más aún, lograron con sorprendente resultado librarse de los desafíos que el narcotráfico, la migración forzada y la violencia institucional impone en sus territorios.

Si como afirma Gilberto López y Rivas (2014), las autonomías son formas de resistencia a través de las cuales etnias y pueblos negados, recuperan o fortalecen su identidad mediante la reivindicación de su cultura, el ejercicio de derechos colectivos y la recreación de estructuras políticas originales, entonces los zapatistas cristalizaron de manera acabada la experiencia autonómica.

Lo cierto es que, aún frente a un constructo amplio y diseminado, la autonomía es un proceso dinámico en el que se construye y apuntala un sujeto político colectivo al calor de la disputa con actores e instituciones estatales, constantemente. Las iniciativas tendientes a integrar a través de políticas indigenistas aggiornadas, propias del siglo XXI, a comunidades y pueblos no cesan y asedian en su afán desmovilizador, a indígenas, sobre todo jóvenes ${ }^{9}$. No faltan instancias de compra de voluntades, ofrecimiento de cargos, otorgamiento de subsidios e intentos de cooptación de líderes que apuntan a minar el proyecto autonómico. No obstante, contrariamente a la intención inicial, el propio proceso de avance del Estado genera una intensidad creciente de la autonomía, una resistencia en la búsqueda de salvaguardar la propia identidad, los modos de vida y el vínculo con la Naturaleza.

La experiencia política de la autonomía desafió al sistema político electoral mexicano en julio de 2018. En el marco del Congreso Nacional Indígena, del cual los pueblos zapatistas forman parte desde hace al menos cuatro décadas, fue elegida una vocera del Concejo Indígena de Gobierno (CIG) representando a 523 comunidades y 43 grupos indígenas de 25 estados de la República mexicana. Su elección implicó el lanzamiento a una precandidatura a la Presidencia de México. La propuesta de gestión del CIG, en la voz de María de Jesús Patricio -más conocida como Marichuy- fue una plataforma comunitaria, antirracista, de izquierda, anticapitalista y antipatriarcal. La candidatura no prosperó como era de esperar, el sistema penaliza a los candidatos independientes que no logran alcanzar un umbral de votos mínimos con representación territorial. Aún así, el zapatismo, una 
vez más se destacó por su capacidad de asombro. La campaña política, las caravanas por el país, los comités de escucha y debate político, mostraron la trascendencia de la dualidad Estado-comunidades autónomas. El límite institucional cristalizado en normas y reglamentos quedó expuesto y en él, la dimensión excluyente de lo político en su dimensión antagónica.

\section{La episteme zapatista}

Los diferentes pueblos que conforman el EZLN tienen perspectivas diferentes del poder, del tiempo, de la organización política, de la religiosidad y la comunicación. Estas ideas, lejos de constituir una unidad homogénea, son relativas y no procuran alcanzar la universalidad. De esta manera, construyen una otra episteme. La episteme zapatista consiste en un conjunto de saberes que, articulados, fungen como cristales para la construcción de interpretaciones sobre la realidad social. Esta episteme no se restringe a la materialidad de lo real, al mundo de los fáctico, sino que permite pensar más allá de lo que acostumbramos a pensar como interpretación de lo que es, y proyectar lo que podría ser. De ese modo, los conocimientos son dinamizados y enriquecidos colectivamente permitiendo visualizar posibilidades de una realidad que excede los límites del presente.

Los saberes zapatistas iluminan aspectos de lo político en el que el antagonismo se expresa a través de prácticas políticas basadas en experiencias de confrontación. De esta manera, abren caminos, señalan rumbos, subrayan obstáculos, anticipan destinos, denuncian desde la exterioridad del sistema estatal dominante la existencia de un modo de ser, estar y hacer política racista y excluyente, proponiendo otro modo de pensar lo común, lo público y lo diverso.

La peculiaridad de la forma en que expresan el quehacer político en su dimensión antagónica, no obstante, no es criticando la vitalidad del sistema político mexicano -y occidental- sino a través de prácticas que, en su ejercicio y con valores ontológicamente democráticos, contradicen y se diferencian de las prácticas dominantes existentes. De esta manera, crean relaciones sociales aparentemente novedosas por su autenticidad, extrañas a las comunes a nuestras sociedades. Son relaciones cercanas, de pequeña escala, solidarias, respetuosas de la Naturaleza, que asumen una perspectiva de poder horizontal. No obstante su popularidad, estas formas no son nuevas y es este uno de los múltiples sentidos que emana de la comprensión de los saberes zapatistas en tanto episteme.

Bajo un esquema discursivo, práctico y teórico propio, heterónomo de las formas revolucionarias que asumieron movimientos políticos pasados, los y las zapatistas establecen relaciones de poder basadas en la igualdad, justificando la dignidad humana. Así, desafían las prácticas agonistas (Mouffe, 2017), de mediación de los conflictos y contradicciones a través de prácticas institucionales estatales en la búsqueda de un consenso conflictual. Entre los zapatistas y el Estado no hay adversarios, tampoco enemigos, hay poderes que en igualdad de condiciones y en un deseado mutuo reconocimiento en virtud de la legitimidad de los órdenes sociales que representan, exigen sentarse a negociar, de igual a igual, márgenes de respeto y autonomía.

Si es cierto que toda práctica revolucionaria requiere de un mito, entonces, tal vez sin haber sido previamente idealizado ni practicado, el mito sea esta vez la suma de proyectos subalternos existentes en México, que exigen respeto a sus formas de organización y producción de la vida.

A su vez, en una sociedad en la que el conocimiento se articula con la dominación, y el saber es poder, reconocer el saber de los y las zapatistas arroja luz sobre las formas de resistencia y construcción de alternativas que disputan la hegemonía del orden capitalista.

Como sabemos, los supuestos que dieron origen a las Ciencias Sociales se articulan en torno de la idea de modernidad. Este ideal moderno se ha cristalizado en cuatro dimensiones básicas: la historia se encuentra regida por la idea de progreso, la sociedad es naturalmente una sociedad liberal, existen separaciones básicas, incuestionables, en la sociedad en el marco del capitalismo, y existe también una superioridad de los saberes producidos como ciencias, por encima de cualquier otro saber (Lander, 2000).

Habiendo desarrollado estos saberes sociales por décadas, la forma de construcción de conocimiento moderno occidental parece estar encontrando sus propios límites. En el presente, abundan los teóricos 
que sostienen que nuestra disciplina no tiene capacidad de dar respuestas concretas, mucho menos explicar, comprender, anticipar o acompañar los vaivenes de la realidad social del siglo XXI. Los y las zapatistas, por el contrario, tienen una concepción propia del poder y sus análisis contienen propuestas diagnósticas, tomas de posición, crítica teórica, justificación y coherencia con la realidad.

Como pocos movimientos sociales, el zapatismo supo ser pop y crear situaciones públicas para mantenerse visible por un buen tiempo modificando constantemente su magnitud y dimensión en tanto fenómeno político y social. Y, con eso establecer enlaces y articulaciones con un conjunto cada vez mayor y más heterogéneo de luchadores sociales (Brancaleone, 2015, p 325. Traducción propia).

Así, pensar al EZLN como agente de una teoría política propia, permite recuperar la singularidad que mucho más que folclórica, acarrea sentidos profundos, estructurantes de las desiguales que definen a la sociedad mexicana, y a través de ella a las occidentales.

Si es cierto que el acceso a la ciencia, y la relación entre ciencia y verdad establece una diferencia radical entre las sociedades occidentales y el resto del mundo (Lander, 2000), entonces, la diferenciación básica entre "la" sociedad que posee la verdad y las otras que no la tienen, sería unánime y por tanto, no habría conocimiento legítimo en la episteme zapatista ni en cualquier otro saber proveniente de la enorme cantidad de pueblos indígenas que habitan nuestro continente. Contra estas ideas también toma postura la episteme zapatista.

En las conferencias de 2007, tituladas 'Ni el centro ni la periferia', Marcos desarrolló un diagnóstico sobre el estado actual de las Ciencias Sociales. Allí, recuperó la idea que sostiene que en América Latina, existe desde hace siglos la reproducción de un saber imitativo, dependiente del pensamiento producido en los países centrales.

Hubo un momento en que las pautas se marcaban desde un centro geográfico y de ahí se iban extendiendo hacia la periferia, como una piedra arrojada en el centro de un estanque. La piedra conceptual tocaba la superficie de la teoría y se producía una serie de ondas que afectaban y modificaban los distintos quehaceres científicos y técnicos adyacentes (Galeano/S. I. Marcos, 2007, p. 5).

Además, en el desarrollo de quehacer teórico, se habría alcanzado un grado de absoluta prescindencia de la realidad para la elaboración de análisis. En ese sentido, la neutralidad, la apuesta por un saber objetivo, habría implicado -en sus palabras- una "obsesión por la higiene antirealidad”. Desde ese punto de vista, los zapatistas asumen que las Ciencias Sociales actuales han entrado en una dinámica propia de las modas.

Las universidades europeas y los institutos tecnológicos de Norteamérica repiten el listado de la moda: París, Roma, Londres, Nueva York (Galeano/S. I. Marcos, 2007).

Aquello que desde su perspectiva fue construyéndose, es el apuntalamiento de la noción que entiende que se pueden transformar las relaciones sociales sin luchar y sin tocar los privilegios que disfrutan los poderosos.

Para dar cuenta de la relación entre la transformación de las condiciones materiales y relaciones sociales, Marcos señala que en las comunidades zapatistas, los avances que se han dado a partir de la construcción de autonomías en materia de gobierno, salud, educación, vivienda, alimentación, participación de las mujeres, comercialización, cultura, comunicación e información, sólo pudieron darse a partir de la recuperación de los medios de producción, en particular, la tierra, los animales y las máquinas que estaban en manos de los grandes propietarios hacendatarios de Chiapas.

Que sostengamos que el núcleo central del dominio capitalista está en la propiedad de los medios de producción, no significa que ignoremos (...) los otros espacios de dominio. Es claro para nosotros que las transformaciones no deben enfocarse sólo a las condiciones materiales. Por eso para nosotros no hay la jerarquía de ámbitos; no sostenemos que la lucha por la tierra es prioritaria sobre la 
lucha de género, ni que ésta es más importante que la del reconocimiento y respeto a la diferencia. Pensamos, en cambio, que todos los énfasis son necesarios y que debemos ser humildes y reconocer que no hay actualmente organización o movimiento que pueda preciarse de cubrir todos los aspectos de la lucha antisistémica, es decir, anticapitalista (S. I. Moisés, 2015, p. 41).

Por todo esto, la propuesta zapatista comprende elementos que pueden contribuir a la visualización de una epistemología propia. Es posible considerar incluso que dicha epistemología guía nuevos planteamientos, formulaciones hipotéticas y preguntas de investigación. Tal vez se requieran además nuevas metodologías que aborden sentires, pensares y concepciones alternativas a la visión de mundo moderno-occidental. El reconocimiento y respeto de saberes ancestrales exige un cambio del lugar de enunciación y una previa aceptación del estado actual de nuestras disciplinas que escasamente se orientan a la resolución de temas y problemas de grupos, colectivos o comunidades autónomas postergadas.

Si Mignolo (2010) propone la desobediencia epistémica y Catherine Walsh (2002) la des-jerarquización de conocimientos en miras a colocarlos en una relación de simetría con otros, desde esta perspectiva proponemos dar un paso al costado y aceptar la interpelación crítica que los y las zapatistas realizan.

Desmenuzar las críticas y denuncias que los indígenas realizan a las Ciencias Sociales actuales por su inoperancia constituye sin duda un primer paso. Luego, cabe detenerse y observar, en silencio. No sólo aprender, del mismo modo que cualquier observador puede aprender del arte de la elegancia del caminar tojolabal, sino admirar cómo ellos y ellas lo hacen. De sus formas de ser y estar en el mundo, de su episteme, se desprenden los conocimientos que insinúan los aportes necesarios.

El saber válido desde nuestras academias probablemente surja de la negación de sus propias prácticas y de la recreación como embrión de esa negación, de nuevas formulaciones. Abrir la intelección a los pedidos, demandas y necesidades de grupos, pueblos o movimientos organizados desde las Ciencias Sociales implica dicho momento de negación si lo que se busca en todo caso es participar de las tensiones que abre el presente y del compás del movimiento de la realidad social.

Efectivamente existe una episteme propia en los movimientos de postergados, excluidos o subalternizados. Permitirnos escuchar y a partir de allí dialogar con sus prácticas más allá de nuestra realidad cercana es condición necesaria para ampliar el horizonte en el que se tejen otras formas de producción de sentido y nuevos lugares de enunciación.

\section{Notas}

1 Esta perspectiva no desconoce la influencia de los movimientos guerrilleros y revolucionarios de los años 70 y 80 en aquello que conformó la "amalgama original" del EZLN, sobre todo en el trabajo desarrollado en la clandestinidad entre 1983 y 1994. Por otra parte, si bien no se logra profundizar analíticamente el presente trabajo, vale destacar la influencia que tuvieron diversos autores latinoamericanos en aspectos clave del derrotero práctico de la autonomía. Conceptos centrales de la pedagogía del oprimido de Paulo Freire están presentes en el caminar preguntando y en el diálogo como instancia de enseñanza/aprendizaje de la propia visión de mundo. Así también la crítica de Frantz Fanon al respecto de no pretender admirar o imitar bajo ninguna circunstancia el mundo del colonizador se materializa en el ejercicio de la autonomía, pues, en las propias tradiciones de los y las zapatistas se encuentran las referencias para la construcción del mundo en que quepan muchos otros mundos.

2 La crítica a la epistemología clásica fue instalada por intelectuales y académicos provenientes de países con larga historia de colonización, de sociedades que por siglos padecieron distintas manifestaciones de violencia en miras a la imposición de un orden económico, político, social y cultural exógeno. En la crítica al eurocentrismo confluyeron varias corrientes teóricas, algunas provenientes de los estudios culturales, filosóficos, sociológicos. El contexto de crítica permitió crear una arena de debate interdisciplinar referida a las condiciones del desarrollo estructural, histórico-cultural y político de las sociedades latinoamericanas. Este espacio crítico y más aún, la metodología de creación de pensamiento que confluye en él, fue denominado pluriversalismo (Grosfoguel, 2013).

3 Entre 15.000 y 25.000 indígenas tzotziles han sido expulsados de sus comunidades "en los últimos 20 
años". En particular, salieron de San Juan Chamula, Mitontic, Zinactan y Amatenango del Valle (CNDH, en base a datos de 1994).

4 La población tojolabal está asentada en pequeñas poblaciones en las montańas y valles que rodean la ciudad de Comitán. Algunos historiadores sostienen que Comitán fue quizá el pueblo tojolabal más grande durante la época colonial, fundado después de la conquista. Fue también el asentamiento de en donde los dueños de las fincas, civiles y religiosos dominicos, tenían sus casas urbanas, tiendas y monasterios.

5 En Zinacantán, por ejemplo, existen 61 cargos divididos en cuatro niveles y cuatro categorías de auxiliares; hay 34 mayordomos, mayores y sacristanes, seguidos en importancia por 14 alféceres y 2 músicos, luego, existe un tercer escalón de 4 regidores y finalmente 2 alcaldes o moletiks acompañados de los alcaldes nuevos.

6 La práctica de los santos parlantes es una pecualiaridad religiosa de la zona central de Chiapas. Deviene de la experiencia de Patrocinio Sánchez, líder espiritual de la región de Ixtacomitán, en la zona central de Chiapas. Se trata del primer santo que se comunica a través de un receptor, en una cajita desde la cual, el propio San Miguel Arcángel cura, da consejos y predice. La noticia más importante transmitida por San Miguelito habría sido la erupción del volcán Chichonal, en 1982, anticipando un desastre natural que generó la migración de una enorme cantidad de familias a la región.

7 Entendemos que el lenguaje es siempre reflejo de una visión de mundo y de relaciones sociales específicas.

8 Al momento de escribir el presente texto, existían sólo cinco Caracoles zapatistas, no obstante, en agosto de 2019 fue anunciada la creación de siete nuevos Caracoles o Centros de Resistencia Autónoma y Rebeldía Zapatista, en Tila, San Cristóbal de las Casas, Ocosingo y Amantenango del Valle.

9 Como sabemos, "el Estado capitalista tiene dos tareas básicamente contradictorias. Por una parte, debe asegurar las condiciones que hagan posible la acumulación y reproducción del capital, lo que lo lleva a adoptar las medidas coercitivas necesarias para que las clases subalternas se acomoden -disciplinen- a la lógica del capital (coerción). Por otra parte, debe legitimar su dominación para hacerla estable, recurriendo a una serie de mecanismos que no se reducen a lo ideológico, sino que implican lógicas propias de la reproducción material, traducidas en gastos sociales destinados a proveer un cierto grado de consenso en las clases dominadas (legitimación). La contradicción entre ambas funciones genera tensiones y sucesivas crisis" (Thwaites Rey, 2005).

\section{BIBLIOGRAFÍA}

ALEJOS GARCIA, José. (1999), "Vencer o morir. Mitología y sociedad entre los choles". Estudios de cultura Maya, 20: 428-441.

ANSALDI, Waldo y GIORDANO, Verónica. (2012), América Latina, la construcción del orden. Tomo I. Buenos Aires, Ariel.

AVILA ROJAS, Odín. (2017), "La experiencia zapatista. Análisis sobre sus prácticas democráticas". Revista de Ciencias Sociales, 31, 42: 195-211.

BASAURI, Carlos. (1931), Los tojolabales, tzeltales y mayas. México, Talleres gráficos de México.

BRANCALEONE, Cassio (2015) Teoria social, democracia e autonomia. Uma interpretação da experiência do autogoverno zapatista. São Paulo, Azougue.

BRENNER, Anita. (1983), Ídolos tras los altares. México, Domés.

CDI - Comisión Nacional para el Desarrollo de los pueblos Indígenas. (2007), Choles, pueblos indígenas del México Contemporáneo. Disponible en: http://www.cdi.gob.mx CDI, México. Acceso: 8 de julio de 2018.

CNDH - Comisión Nacional de los Derechos Humanos. (1994), Recomendación 58/94. Disponible en: www.cndh.org.mx/sites/all/doc/ Recomendaciones/1994/ Acceso: 8 de julio de 2018.

CUEVAS, J. H. (2007), “Salud y autonomía: el caso de Chiapas”. Health Systems Knowledge Network. Disponible en: www.who.int/social_determinants/ map/en. Acceso: 12 de noviembre de 2018.

DE VOS, Jan. (1980), La paz de Dios y del rey. La conquista de la selva Lacandona. México, Fonapas.

DE VOS, Jan. (1988), Viajes al desierto de la soledad. Cuando la selva Lacandona aún era selva. México, SEP-CIESAS.

De VOS, Jan. (1994), Vivir en frontera. La experiencia de los indios de Chiapas. México, CIESAS-INI.

DURHAM, Eunice (1984), "Cultura e Ideología”, Dados, 27, 1:71-89.

DUSSEL, Enrique. (2000), Europa, modernidad y eurocentrismo. Buenos Aires, CLACSO. 
EGAN, Daniel. (2006) Rethinking the Zapatistas: Frantz Fanon and Resistance to Neoliberalism. Humanity and Society, 30, 1: 67-83.

ESCALONA VICTORIA, José Luis. (2009), Política del Chiapas rural contemporáneo. México, UNAM.

ESCOBAR, Arturo. (2011), "Conversaciones sobre la diferencia. Encuentro con Arturo Escobar”. Entrevista colectiva. Participantes: Máximo Badaró, Marita Carozzi, Arturo Escobar, Claudia Fonseca, Alejandro Grimson, Pablo Semán. En Tabula rasa.

EZLN. (2013), "Ellos y nosotros. VI. Las miradas". Comunicado del 6 de febrero. Disponible en: http://enlacezapatista.ezln.org.mx/2013/02/06/ ellos-y-nosotros-vi-las-miradas/ Acceso: $11 \mathrm{de}$ julio de 2018.

EZLN. (2014), "Entre la luz y la sombra”. Comunicado del 25 de mayo. Enlace zapatista. Disponible en: http://enlacezapatista.ezln.org.mx/2014/05/25/ entre-la-luz-y-la-sombra/ Acceso: 10 de julio de 2018

FAVRE, Henri. (1973), Cambio y continuidad entre los mayas de México. Contribución al estudio de la situación colonial en América Latina. México, INI.

FERNANDEZ CHRISTLIEB, Paulina. (2012) "Justicia autónoma frente a justicia oficial". Estudios Políticos, México, 26: 37-55.

GHILINO, Anabela. (2015), "Una aproximación a "lo político" y "la política" desde la perspectiva de Ernesto Laclau y Jacques Ranciére". Opción, 31, 78: 138-144.

GONZALEZ CASANOVA, Pablo (1995), "Causas de la rebelión en Chiapas". Politica y Sociedad, 17: 83-94. México.

GROSFOGUEL, Ramón. (2013), Entrevista a Ramón Grosfoguel, por Luis Martínez Andrade. Metapolitica, 83. Disponible en: www.analectica. org/articulos/mtzandrade-grosfoguel/. Acceso: 7 de julio de 2018.

HERNANDEZ NAVARRO, Luis. (2012), "Derrumbe y renacimiento en el mundo maya zapatista”. La Jornada, 22 de diciembre. (Sentido contrario).

LACLAU, Ernesto. (2010), Hegemonía y estrategia socialista. Buenos Aires, 2010.
LANDER, Edgardo. (2000), La colonialidad del saber. Eurocentrismo y ciencias sociales. Perspectivas latinoamericanas. Buenos Aires, CLACSO.

MIGNOLO, Walter. (2010), Desobediencia epistémica. Retórica de la modernidad, lógica de la colonialidad y gramática de la descolonialidad. Buenos Aires, Ediciones del Signo.

MORALES BERMUDEZ, Jesús. (1999), Antigua palabra narrativa indigena $C h$ 'ol. México. Tuxtla, Unicach-Plaza y Valdés editores.

MOUFFE, Chantal. (2014), Agonistica, pensar el mundo politicamente. Buenos Aires, FCE.

CASTRO-GOMEZ, Santiago y GROSFOGUEL, Ramón -eds.- (2007), El giro decolonial. Reflexiones para una diversidad epistémica más allá del capitalismo global. Bogotá, Siglo del Hombre.

LENKERSDORF, Carlos. (2008), Aprender a escuchar. Enseñanzas maya-tojolabales. México, Plaza y Valdés.

PADIERNA JIMENEZ (2013) "Mujeres zapatistas; la inclusión de las demandas de género". Argumentos, 26: 133-142.

PAEZ MARTINEZ, Ruth. (2011) "Narración mítica: necesario tejido espiritual en la formación de los niños", Revista Iberoamericana de Educación, 54/5, 1-12. Organización de Estados Americanos para la Educación, la Ciencia y la Cultura (OEI). Disponible en:

PANIAGUA MIJANGOS, Jorge Gustavo. (2008), “De los pueblos indios a la ficción antropológica: los sistemas de cargos en la etnografía de los altos de Chiapas. Antecedentes, Balance y Perspectivas". Pueblos y Fronteras Digital, 5: 1-37.

ROSEBERRY, William. (2002) "Hegemonía y lenguaje contencioso", en JOSEPH, G. y NUGENT, D. -Comps.-, Aspectos cotidianos de la formación del Estado. La revolución y la negociación del mando en el México moderno. México, Era.

SCOTT, James. (2009), The art of not being governed. An anarchist history of upland Southeast Asia. Estados Unidos, Yale University Press.

SCOTT, James. (2000) Los dominados y el arte de la resistencia. Discursos ocultos. México, Era. 
S. I. Moises (2015) Economía política desde las comunidades I y II, en El pensamiento critico rente a la hidra capitalista. Documentos del EZLN. Disponible en: www.enlacezapatista.org. Acceso: 8 de agosto de 2019.

S. I. Marcos (2007) "Ni el centro ni la periferia", conferencias del Primer coloquio internacional Andrés Aubry in memoriam. San Cristóbal de las Casas, diciembre de 2007. Disponible en: http://seminarioscideci. org/1er-coloquio-2007. Acceso: 6 de agosto de 2019.
THWAITES REY, Mabel. (2005), "Estado: ¿Qué Estado?”, en THWAITES REY, Mabel y LOPEZ, Andrea -eds.-, Entre tecnócratas globalizados y politicos clientelistas. Derrotero del ajuste neoliberal en el Estado argentino. Buenos Aires, Prometeo.

VOGT, Evon. (1992), Los zinacantecos. Un pueblo tzotzil de los Altos de Chiapas. México, INI.

WALSH, Catherine. (2000), Pensamiento critico y matriz (de)colonial. Reflexiones latinoamericanas. Quito, Abya-Yala Editores. 


\section{LA EPISTEME ZAPATISTA: OTRA FORMA DE VER EL MUNDO Y HACER POLÍTICA}

\section{Victoria Inés Darling}

Palabras claves: Política; Pueblos indígenas; Autonomía; Decolonialidad.

El artículo problematiza la singularidad política de los zapatistas de México. Se analiza el derrotero de sus formas de organización autónoma como resultado del proceso de acumulación política que hasta el presente confronta y va a destiempo de la institucionalidad política mexicana. Al estudiar aspectos distintivos de las etnias que conforman al movimiento, se aborda la forma en que estos pueblos ocuparon el territorio confrontando con la estructura agraria dominante, la finca, su modo de producción, la religiosidad, así como sus mitos. De esta manera, se articulan saberes que componen aquello que denominamos episteme zapatista. Contribuyendo al campo de estudios sociológicos de los movimientos sociales vis a vis las perspectivas críticas de la modernidad/colonialidad, la investigación releva de manera interdisciplinar aspectos de la vida cotidiana colectiva de los indígenas zapatistas en consonancia con los procesos políticos que impulsaron al enfrentar las formas estatales de construcción del orden.

\section{A EPISTEME ZAPATISTA: UMA OUTRA FORMA DE VER O MUNDO E FAZER POLÍTICA}

\section{Victoria Inés Darling}

Palavras-chave: Política; Povos indígenas; Autonomia; Decolonialidade.

$\mathrm{O}$ artigo problematiza a singularidade da política dos zapatistas do México. A trajetória das suas formas de organização autônoma é analisada como resultado do processo de acumulação política que até o presente confronta com a institucionalidade política mexicana. Aspectos distintivos dos grupos étnicos que compóem o movimento são estudados como a maneira na qual eles ocuparam o território confrontado com a estrutura agrária da fazenda, o seu modo de produção, a sua religiosidade, e a su construção de mitos. Deste modo, os conhecimentos sao articulado num complexo que chamamos de episteme zapatista. Contribuindo ao campo de estudos sociológicos dos movimentos sociais vis a vis as perspectivas críticas da modernidade/colonialidade, a pesquisa aborda de maneira interdisciplinar aspectos do cotidiano coletivo dos povos indígenas e os seus processos políticos que, persistentes, ainda enfrentam a ordem do Estado.

\section{THE ZAPATIST EPISTEME: A DIFFERENT WAY OF SEEING THE WORLD AND MAKING POLITICS}

\author{
Victoria Inés Darling
}

Keywords: Politics; Indigenous people; Autonomy; Decoloniality.

The article problematizes the singularity of the political construction of the Zapatists in Mexico. We analyze its forms of autonomous organization, considering them as a result of a political accumulation process that confronts and goes in the opposite direction of the political order of Mexican institutions. Considering aspects of the different ethnic groups that joined the movement, we describe the way they occupied the territory in relation to the agrarian order of la finca, their mode of production, their religiosity, and their myths. A Zapatist episteme articulates these different elements of knowledge. This research reveals the collective daily life of the indigenous people of the southern México in consonance with political processes that still confront the State order. It also contributes to the sociological field of social movements and the critical perspectives of modernity / coloniality, taking an interdisciplinary approach. 


\section{L'EPISTEME ZAPATISTE: UNE AUTRE VISION DU MONDE ET DE LA POLITIQUE}

\section{Victoria Inés Darling}

Mots-clés: Politique; Peuples amérindiens; Autonomie; Décolonialité.

Cet article étudie la singularité de la politique des zapatistes du Mexique. Ses formes d'organisation autonome sont analysées comme résultat du processus d'accumulation politique qui, jusqu'à aujourd'hui, s'oppose à l'institutionnalisation politique. Différents aspects des groupes ethniques qui composent le mouvement sont abordés, comme l'occupation du territoire face à la structure agraire de la propriété agricole, le mode de production, la religiosité ou encore la construction de mythes. Les connaissances sont articulées à travers ce que nous nommons l'épistémè zapatiste. Pour contribuer au champ d'études sociologiques des mouvements sociaux vis-à-vis $e t$ avec les perspectives critiques de la modernité/colonialité, la recherche aborde de manière interdisciplinaire des éléments du quotidien collectif des peuples amérindiens et leurs processus politiques qui continuent d'affronter l'ordre de l'État. 